\title{
Research on Calculation of Wind Resistance of 20-Storeys High-Rise Building Structure
}

\author{
Yang Lujiang ${ }^{1, a}$, Chen Gong ${ }^{* 1,2, b}$ and Yang Hongmei ${ }^{1, c}$ \\ ${ }^{1}$ Chengdu Textile College, Chengdu, China, 611731 \\ ${ }^{2}$ Chengdu University of Technology, Chengdu, China, 610059 \\ a724422011@qq.com, b114032216@qq.com, c33205524@qq.com
}

\begin{abstract}
Keywords: wind resistance, internal stress response, high-rise building, research
Abstract: Frame structure consists of frame columns, frame beams, etc. The longitudinal stiffness of frame structure is obviously better than lateral stiffness of frame structure. Lateral stiffness and internal stress response of lateral frame should be mainly considered, when frame structure is calculated and analysed under dynamic load. Frame structure system is optimized, and the space of lateral frame columns is set to zero. At present, lateral frame columns are close to each other in the frame structure, which changes into shear wall structure. Since shear wall structure can be considered as the structure close to each other where the space of frame columns is set to zero, lateral stiffness of shear wall structure is obviously better than lateral stiffness of frame structure. Research is based on stress characteristic of frame structure and shear wall structure. Firstly, stress characteristic of structure under the action of wind load has been simulated. Secondly, internal stress response of structure under the action of wind load has been calculated by numerical simulation software "PKPM", also internal stress response of frame structure and shear wall structure under the action of wind load has been reached. Thirdly, the internal stress response of structure has been compared and analyzed. Finally the conclusions are made.
\end{abstract}

\section{Introduction}

Frame structure consists of frame columns, frame beams, etc. The longitudinal stiffness of frame structure is obviously better than lateral stiffness of frame structure. Lateral stiffness and internal stress response of lateral frame should be mainly considered, when frame structure is calculated and analysed under dynamic load. Frame structure system is optimized, and the space of lateral frame columns is set to zero. At present, lateral frame columns are close to each other in the frame structure, which changes into shear wall structure. Since shear wall structure can be considered as the structure close to each other where the space of frame columns is set to zero, lateral stiffness of shear wall structure is obviously better than lateral stiffness of frame structure.

\section{Establishment of Structure Technical Parameter}

The modeling parameters of the computer simulation building model are as follows. The building structure is office building with single aisle, where is set with light sound insulation wall. The openings of shear wall and weight of partition wall are not considered. Standard value of permanent load is $3.5 \mathrm{KN} / \mathrm{m}^{2}$. According to load code for the design of building structures(GB 50009-2012), standard value of variable load is $2.0 \mathrm{KN} / \mathrm{m}^{2}$. Corrected basic wind pressure is $0.1 \mathrm{KN} / \mathrm{m}^{2}$, and ground roughness is type A. Considering vertical wind load vibration, shape coefficient of each section in the structure is 1.3 . Space of vertical grid is $5 \mathrm{~m} \times 10$, and space of horizontal grid is $5 \mathrm{~m}+2.5 \mathrm{~m}+5 \mathrm{~m}$, layer height is $3 \mathrm{~m}$. In the frame structure, section size of column is $500 \mathrm{~mm} \times 500 \mathrm{~mm}$, section size of beam is $300 \mathrm{~mm} \times 550 \mathrm{~mm}$ and $250 \mathrm{~mm} \times 500 \mathrm{~mm}$. In the shear wall structure, thickness of shear wall is $500 \mathrm{~mm}$ which is set along the lateral grid, also section size of connecting beam is $300 \mathrm{~mm} \times 550 \mathrm{~mm}$, $250 \mathrm{~mm} \times 500 \mathrm{~mm}$. Thickness of floor in the structure is $120 \mathrm{~mm}$. According to code for design of concrete structures(GB 50010 - 2010), strength level of concrete of frame column, frame beam, shear wall and connecting beam is C40. Strength level of concrete of casting floor is C30. Type of vertical stressed steel bar in the frame column, frame beam, shear wall, connecting beam and casting floor is 
HRB400, type of stirrups is HPB300. 20-storeys frame structure is model 1, and 20-storeys shear wall structure is model 2. Model 1 is shown by Figure 1, Model 2 is shown by Figure 2.

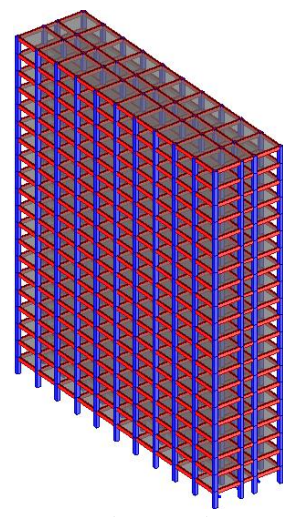

Figure 1

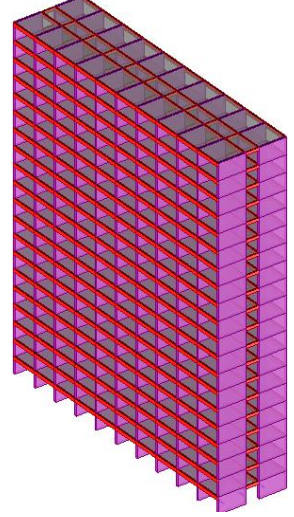

Figure 2

\section{Numerical Simulation Results}

Internal stress response of the floor in the structure under wind load is shown by table 1, table 2 . Comparative analysis of whole stability in model 1 and model 2 under wind load is shown by table 3 . Comparative analysis of comfortable in model 1 and model 2 under wind load is shown by table 4 . In table 1 and table 2, WL $\mathrm{x}$ and $\mathrm{WL}_{\mathrm{y}}$ are wind load of floor in the $\mathrm{X}$ direction and $\mathrm{Y}$ direction, $\mathrm{Q}_{\mathrm{x}}$ and $\mathrm{Q}_{\mathrm{y}}$ are shear force of floor in the $\mathrm{X}$ direction and $\mathrm{Y}$ direction, $\mathrm{Mov}_{\mathrm{x}}$ and $\mathrm{Mov}_{\mathrm{y}}$ are tumble moment of floor in the $\mathrm{X}$ direction and $\mathrm{Y}$ direction. In table 3, $\mathrm{MR}_{\mathrm{x}}$ and $\mathrm{MR}_{\mathrm{y}}$ are anti-tumble moment of overall model in the $\mathrm{X}$ direction and $\mathrm{Y}$ direction, $\mathrm{MOV}_{\mathrm{x}}$ and $\mathrm{MOV}_{\mathrm{y}}$ are tumble moment of overall model in the $\mathrm{X}$ direction and $\mathrm{Y}$ direction, $\mathrm{MR}_{\mathrm{x}} / \mathrm{MOV}_{\mathrm{y}}$ and $\mathrm{MR}_{\mathrm{y}} / \mathrm{MOV}_{\mathrm{y}}$ are safety stability coefficient of overall model in the $\mathrm{X}$ direction and $\mathrm{Y}$ direction, $\mathrm{Z}(0)_{\mathrm{x}}$ and $\mathrm{Z}(0)_{\mathrm{y}}$ are zero zone of overall model in the $\mathrm{X}$ direction and $\mathrm{Y}$ direction. In addition to dimensionless measures, the measures of wind load and shear force are $\mathrm{KN}$, the measures of tumble moment and anti-tumble moment are $\mathrm{KN} \cdot \mathrm{m}$.

Table 1 Internal stress response of the floor in model 1 under wind load

\begin{tabular}{ccccccccccccccc}
\hline Floor & $\mathrm{WL}_{\mathrm{x}}$ & $\mathrm{Q}_{\mathrm{x}}$ & $\mathrm{Mov}_{\mathrm{x}}$ & $\mathrm{WL}_{\mathrm{y}}$ & $\mathrm{Q}_{\mathrm{y}}$ & $\mathrm{Mov}_{\mathrm{y}}$ & Floor & $\mathrm{WL}_{\mathrm{x}}$ & $\mathrm{Q}_{\mathrm{x}}$ & Mov $_{\mathrm{x}}$ & $\mathrm{WL}_{\mathrm{y}}$ & $\mathrm{Q}_{\mathrm{y}}$ & $\mathrm{Mov}_{\mathrm{y}}$ \\
\hline 20 & 14.06 & 14.1 & 42.2 & 54.36 & 54.4 & 163.1 & 10 & 10.48 & 135.2 & 2551.1 & 40.92 & 525.1 & 9892.3 \\
19 & 13.71 & 27.8 & 125.5 & 53.04 & 107.4 & 485.3 & 9 & 10.08 & 145.3 & 2986.9 & 39.43 & 564.5 & 11585.9 \\
18 & 13.35 & 41.1 & 248.9 & 51.72 & 159.1 & 962.6 & 8 & 9.67 & 154.9 & 3451.7 & 37.86 & 602.4 & 13393.0 \\
17 & 13.00 & 54.1 & 411.2 & 50.41 & 209.5 & 1591.2 & 7 & 9.24 & 164.2 & 3944.3 & 36.20 & 638.6 & 15308.7 \\
16 & 12.65 & 66.8 & 611.6 & 49.11 & 258.6 & 2367.1 & 6 & 8.77 & 173.0 & 4463.2 & 34.41 & 673.0 & 17327.6 \\
15 & 12.30 & 79.1 & 848.8 & 47.79 & 306.4 & 3286.4 & 5 & 8.26 & 181.2 & 5006.8 & 32.47 & 705.4 & 19444.0 \\
14 & 11.95 & 91.0 & 1121.9 & 46.47 & 352.9 & 4345.1 & 4 & 7.70 & 188.9 & 5573.5 & 30.29 & 735.7 & 21651.2 \\
13 & 11.59 & 102.6 & 1429.8 & 45.13 & 398.0 & 5539.2 & 3 & 7.04 & 196.0 & 6161.4 & 27.76 & 763.5 & 23941.6 \\
12 & 11.23 & 113.9 & 1771.3 & 43.76 & 441.8 & 6864.6 & 2 & 6.24 & 202.2 & 6768.0 & 24.66 & 788.2 & 26306.1 \\
11 & 10.86 & 124.7 & 2145.5 & 42.37 & 484.2 & 8317.1 & 1 & 5.74 & 207.9 & 7391.8 & 22.79 & 810.9 & 28738.9 \\
\hline
\end{tabular}

Table 2 Internal stress response of the floor in model 2 under wind load

\begin{tabular}{ccccccccccccccc}
\hline Floor & $\mathrm{WL}_{\mathrm{x}}$ & $\mathrm{Q}_{\mathrm{x}}$ & $\mathrm{Mov}_{\mathrm{x}}$ & $\mathrm{WL}_{\mathrm{y}}$ & $\mathrm{Q}_{\mathrm{y}}$ & $\mathrm{Mov}_{\mathrm{y}}$ & Floor & $\mathrm{WL}_{\mathrm{x}}$ & $\mathrm{Q}_{\mathrm{x}}$ & $\mathrm{Mov}_{\mathrm{x}}$ & $\mathrm{WL}_{\mathrm{y}}$ & $\mathrm{Q}_{\mathrm{y}}$ & $\mathrm{Mov}_{\mathrm{y}}$ \\
\hline 20 & 13.97 & 14.0 & 41.9 & 54.01 & 54.0 & 162.0 & 10 & 10.43 & 134.4 & 2535.0 & 40.74 & 522.2 & 9835.0 \\
19 & 13.61 & 27.6 & 124.6 & 52.71 & 106.7 & 482.2 & 9 & 10.04 & 144.4 & 2968.3 & 39.26 & 561.5 & 11519.4 \\
18 & 13.27 & 40.8 & 247.2 & 51.41 & 158.1 & 956.6 & 8 & 9.63 & 154.1 & 3430.5 & 37.71 & 599.2 & 13316.9 \\
17 & 12.92 & 53.8 & 408.5 & 50.12 & 208.3 & 1581.4 & 7 & 9.20 & 163.3 & 3920.2 & 36.06 & 635.2 & 15222.6 \\
16 & 12.58 & 66.3 & 607.5 & 48.83 & 257.1 & 2352.6 & 6 & 8.74 & 172.0 & 4436.2 & 34.29 & 669.5 & 17231.2 \\
15 & 12.23 & 78.6 & 843.2 & 47.53 & 304.6 & 3266.4 & 5 & 8.23 & 180.2 & 4976.8 & 32.36 & 701.9 & 19336.8 \\
14 & 11.88 & 90.5 & 1114.6 & 46.23 & 350.8 & 4318.9 & 4 & 7.67 & 187.9 & 5540.5 & 30.20 & 732.1 & 21533.0 \\
13 & 11.53 & 102.0 & 1420.5 & 44.90 & 395.7 & 5506.2 & 3 & 7.02 & 194.9 & 6125.2 & 27.69 & 759.8 & 23812.3 \\
12 & 11.17 & 113.2 & 1760.0 & 43.55 & 439.3 & 6824.0 & 2 & 6.22 & 201.1 & 6728.6 & 24.60 & 784.4 & 26165.4 \\
11 & 10.81 & 124.0 & 2131.9 & 42.17 & 481.5 & 8268.4 & 1 & 5.73 & 206.9 & 7349.2 & 22.76 & 807.1 & 28586.8 \\
\hline
\end{tabular}


Table 3 Comparative analysis of whole stability of model 1 and model 2 under wind load

\begin{tabular}{ccccccccc}
\hline Model & $\mathrm{MR}_{\mathrm{x}}$ & $\mathrm{MOV}_{\mathrm{x}}$ & $\mathrm{MR}_{\mathrm{x}} / \mathrm{MOV}_{\mathrm{x}}$ & $\mathrm{Z}(0)_{\mathrm{x}}$ & $\mathrm{MR}_{\mathrm{y}}$ & $\mathrm{MOV}_{\mathrm{y}}$ & $\mathrm{MR}_{\mathrm{y}} / \mathrm{MOV}_{\mathrm{y}}$ & $\mathrm{Z}(0)_{\mathrm{y}}$ \\
\hline Model 1 & 3563593.8 & 8317.4 & 428.45 & 0.00 & 890898.4 & 32437.8 & 27.46 & 0.00 \\
Model 2 & 4986719.5 & 8274.6 & 602.65 & 0.00 & 1246680.9 & 32284.9 & 38.61 & 0.00 \\
\hline
\end{tabular}

Table 4 Comparative analysis of comfort of model 1 and model 2 under wind load

\begin{tabular}{cccccccccccc}
\hline \multirow{2}{*}{ Model } & $\begin{array}{c}\text { Direc } \\
\text { tion }\end{array}$ & $\begin{array}{c}\text { Pulsation } \\
\text { increasing } \\
\text { coefficient }\end{array}$ & $\begin{array}{c}\text { Pulsation } \\
\text { influencing } \\
\text { coefficient }\end{array}$ & $\begin{array}{c}\text { Body type } \\
\text { coefficient }\end{array}$ & $\begin{array}{c}\text { Reproductive } \\
\text { period } \\
\text { adjustment } \\
\text { factor }\end{array}$ & $\begin{array}{c}\text { Windward } \\
\text { area }\left(\mathrm{m}^{2}\right)\end{array}$ & $\begin{array}{c}\text { Wind } \\
\text { pressure } \\
(\mathrm{KPa})\end{array}$ & $\begin{array}{c}\text { Basic } \\
\text { cycle } \\
(\mathrm{s})\end{array}$ & $\begin{array}{c}\text { Downwind } \\
\text { acceleration } \\
\left(\mathrm{m} / \mathrm{s}^{2}\right)\end{array}$ & $\begin{array}{c}\text { Lateral wind } \\
\text { acceleration } \\
\left(\mathrm{m} / \mathrm{s}^{2}\right)\end{array}$ \\
\hline \multirow{2}{*}{ Model 1 } & $\mathrm{X}$ & 1.32 & 0.53 & 1.30 & 1.00 & 75.00 & 0.10 & 0.38 & $4.91 \mathrm{E}-03$ & $1.40 \mathrm{E}-03$ \\
& $\mathrm{Y}$ & 1.32 & 0.50 & 1.30 & 1.00 & 300.00 & 0.10 & 0.38 & $1.87 \mathrm{E}-02$ & $1.40 \mathrm{E}-03$ \\
Model 2 & $\mathrm{X}$ & 1.26 & 0.53 & 1.30 & 1.00 & 75.00 & 0.10 & 0.38 & $3.33 \mathrm{E}-03$ & $6.50 \mathrm{E}-04$ \\
& $\mathrm{Y}$ & 1.26 & 0.50 & 1.30 & 1.00 & 300.00 & 0.10 & 0.38 & $1.27 \mathrm{E}-02$ & $6.50 \mathrm{E}-04$ \\
\hline
\end{tabular}

\section{Analysis of Calculation Results}

In table 1, table 2, the wind load is gradually increasing with the increase of the floors, because of increasing wind load with increasing floors. The phenomenon demonstrates that people who lives in the high-rise building feels wind load action more easily than people who lives in the low-rise building in our daily life. Model 1 is frame structure, model 2 is shear wall structure, action area of wind load of frame structure is more than action area of wind load of shear wall structure in the case of the same wind pressure, so wind load of model 1 is more than wind load of model 2 on the same floor. The models are simplified to cantilever beams which are sustaining on the foundation to simulate the stress behavior when the models are sustaining the wind load. According to cantilever beam method and isolation method of theoretical mechanics, shear force on the top in the building structure is minimum, and shear force is gradually increasing with the decrease of the floors. On the same floor, wind load of model 1 is more than wind load of model 2, so shear force of model 1 is more than shear force of model on the same floor. Similarly, tumble moment of model 1 is more than tumble moment of model 2 on the same floor.

In table 3, according to numerical simulation analysis on internal stress response of frame structure and shear wall structure under the action of wind load, we can conclude that tumble moment of model 1 is more than tumble moment of model 2 on the same floor, so tumble moment of overall model 1 is more than tumble moment of overall model 2 . However, the lateral stiffness of shear wall structure is better than the lateral stiffness of frame structure under the same conditions, anti-tumble moment of overall model 1 is obviously better than tumble moment of overall model 2, also safety stability coefficient of overall model 2 is obviously more than safety stability coefficient of overall model 1.

In table 4, the lateral stiffness of model 1 is fewer than the lateral stiffness of model 2, and model 1 is softer than model 2. So the pulsation increasing coefficient of model 1 is more than the pulsation increasing coefficient of model 2. Similarly, under the wind load, the acceleration acting on the soft structure is more than the acceleration acting on the hard structure, so the wind acceleration of model 1 is more than the wind acceleration of model 2. The comfort of model 2 is better than the comfort of model 1 .

\section{Conclusions}

In summary, the lateral stiffness of shear wall structure is better than the lateral stiffness of frame structure under the same conditions, and the floor stress of frame structure is more than the floor stress of shear wall structure. But safety stability coefficient of overall shear wall structure is obviously better than safety stability coefficient of overall frame structure. We can conclude that the motion geometric parameters of shear wall structure are better than the motion geometric parameters of frame structure, such as displacement, displacement angle, etc. Shear wall structure is applicable to 
high-rise building structures, buildings structures with high seismic fortification level and high wind resistance requirements, building structures with higher displacement and deformation requirements.

\section{Technology Outlook}

Numerical Simulation Analysis is the conventional way in the stress calculation and analysis of building structures, we can use different kinds of numerical simulation softwares to verify the results, also we can use similarity principle to do the indoor physical simulation test, in order to verify the results, such as physical simulation test of indoor shaking table, indoor jack loading test, indoor dynamic load test, indoor wind tunnel test, etc.

\section{Acknowledgements}

This research was financially supported by the 2015 Research Project of Chengdu Textile College (Grant No.2015fzlkc06). Corresponding author is Chen Gong.

\section{References}

[1] Yang Lujiang, Liu Dewen, Guo Zhongli, Li Jing, Dai Bihui. Engineering Mechanics in Whipping Effect of High-Rise Building, Advanced Research on Mechanics Manufacturing Engineering and Applied Technology. 2014.

[2] Yang Lujiang, Liu Dewen, Guo Zhongli, Li Jing, Dai Bihui. Engineering Mechanics in High-Rise Building with Irregular Planner, Advanced Research on Mechanics Manufacturing Engineering and Applied Technology. 2014.

[3] Chen Gong, Xian Jinhong. Calculation Analysis And Application Of Shear Wall In The High-Rise Building Seismic, Science Technology and Engineering. 2013. 